\title{
Slow potentials encode intercellular coupling and insulin demand in pancreatic beta cells
}

\author{
Fanny Lebreton • Antoine Pirog • Isma Belouah • \\ Domenico Bosco • Thierry Berney • Paolo Meda • \\ Yannick Bornat • Bogdan Catargi • Sylvie Renaud • \\ Matthieu Raoux • Jochen Lang
}

Received: 7 November 2014 / Accepted: 23 February 2015 / Published online: 19 March 2015

(C) Springer-Verlag Berlin Heidelberg 2015

\begin{abstract}
Aims/hypothesis Ion fluxes constitute a major integrative signal in beta cells that leads to insulin secretion and regulation of gene expression. Understanding these electrical signals is important for deciphering the endogenous algorithms used by islets to attain homeostasis and for the design of new sensors for monitoring beta cell function.

Methods Mouse and human islets were cultured on multielectrode arrays (MEAs) for 3-13 days. Extracellular electrical activities received on each electrode were continuously amplified and recorded for offline characterisation.

Results Differential band-pass filtering of MEA recordings of mouse islets showed two extracellular voltage waveforms: action potentials (lasting 40-60 ms) and very robust slow potentials (SPs, lasting $800-1,500 \mathrm{~ms}$ ), the latter of which
\end{abstract}

M. Raoux and J. Lang contributed equally to this work.

Electronic supplementary material The online version of this article (doi:10.1007/s00125-015-3558-z) contains peer-reviewed but unedited supplementary material, which is available to authorised users.

F. Lebreton $\cdot$ I. Belouah $\cdot$ B. Catargi $\cdot$ M. Raoux $\cdot$ J. Lang $(\bowtie)$ CNRS UMR 5248, Chimie et Biologie des Membranes et Nano-objets, Université de Bordeaux, Batiment B14, Allée Geoffroy St Hilaire, CS90063, 33615 Pessac, France

e-mail: jochen.lang@u-bordeaux.fr

F. Lebreton $\cdot$ I. Belouah $\cdot$ M. Raoux $\cdot$ J. Lang

Department of Sciences \& Technology, Université de Bordeaux,

Bordeaux, France

A. Pirog $\cdot$ Y. Bornat $\cdot$ S. Renaud

CNRS UMR 5218, Laboratoire de l'Intégration du Matériau au

Système, Institut Polytechnique de Bordeaux, Talence, France

D. Bosco $\cdot$ T. Berney

Centre Universitaire Romand de Transplantation, Département de

Chirurgie, Hôpital Universitaire de Genève, Genève, Switzerland have not been described previously. The frequency of SPs directly correlated with glucose concentration, peaked at $10 \mathrm{mmol} / \mathrm{l}$ glucose and was further augmented by picomolar concentrations of glucagon-like peptide-1. SPs required the closure of ATP-dependent potassium channels as they were induced by glucose or glibenclamide but were not elicited by KCl-induced depolarisation. Pharmacological tools and the use of beta cell specific knockout mice showed that SPs reflected cell coupling via connexin 36 . Moreover, increasing and decreasing glucose ramps showed hysteresis with reduced glucose sensitivity during the decreasing phase. SPs were also observed in human islets and could be continuously recorded over $24 \mathrm{~h}$.

Conclusions/interpretation This novel electrical signature reflects the syncytial function of the islets and is specific to beta

D. Bosco $\cdot$ T. Berney $\cdot$ P. Meda

Département de Physiologie Cellulaire et Métabolisme, Centre

Médical Universitaire, Genève, Switzerland

D. Bosco P. Meda

Université de Genève, Genève, Switzerland

B. Catargi

Service d'Endocrinologie, Centre Hospitalier, Universitaire de Bordeaux, Bordeaux, France

Present address:

I. Belouah

INRA UMR 1332 Biologie du Fruit et Pathologie,

Villenave d'Ornon, France 
cells. Moreover, the observed hysteresis provides evidence for an endogenous algorithm naturally present in islets to protect against hypoglycaemia.

Keywords Electrophysiology · Extracellular recordings · Glucose homeostasis · Islets of Langerhans · Signalling

$\begin{array}{ll}\text { Abbreviations } \\ \text { AP } & \text { Action potential } \\ \text { CX36 } & \text { Connexin 36 } \\ \text { EC }_{50} & \text { Median effective concentration } \\ \text { Flox } & \text { Cx36 }^{\text {Flox(CFP)/Flox(CFP) }} \\ \text { GLP-1 } & \text { Glucagon-like peptide-1 } \\ \text { GTT } & \text { Glucose tolerance test } \\ \text { K }_{\text {ATP }} & \text { ATP-dependent potassium } \\ \text { MEA } & \text { Multielectrode array } \\ \text { OGTT } & \text { Oral glucose tolerance test } \\ \text { RIP-Cre } & \text { Cx36 } \\ \text { SP } & \text { Slox(CFP)/Flox(CFP) } \\ \text { SIP-Cre } \\ \text { WT } & \text { Wild-type }\end{array}$

\section{Introduction}

Islets play a central role in nutrient homeostasis acting as sensors and storage as well as release sites for the principal hormones involved in glucose regulation [1]. Beta cells are activated by glucose, the metabolism of which induces a change in coupling factors, including an increase in the ratio of ATP/ADP leading to the closure of ATP-dependent potassium $\left(\mathrm{K}_{\mathrm{ATP}}\right)$ channels. The ensuing membrane depolarisation opens voltage-dependent channels [1] and the resulting calcium influx regulates insulin exocytosis as well as gene expression. Beta cells are an ideal sensor for insulin demand since they are also sensitive to hormones that relay the status of the organism. Incretins, such as glucagon-like peptide-1 (GLP-1), act via G-protein coupled receptors to potentiate the electrical response and secretion of insulin [2]. By contrast, stress hormones like adrenaline (epinephrine) reduce electrical activity and hormone exocytosis during physical activity [3]. Therefore, changes in cell membrane potential represent an integrative signal read-out that encodes the body's demand for insulin.

Glucose-induced metabolism-secretion coupling has been described in great detail and is characterised by oscillations of metabolites, second messengers, membrane potential and insulin secretion, with a frequency ranging from one event per $10 \mathrm{~s}$ to one per $1 \mathrm{~min}$ or per several $\mathrm{min}$ in the case of insulin secretion [4]. Oscillations may be part of endogenous algorithms that beta cells use for nutrient homeostasis. Moreover, they are disrupted under pathological conditions, such as lipotoxicity [5] or type 2 diabetes [6]. Investigating integrative signals, such as electrical activity, is required for deciphering endogenous algorithms used by islets to attain homeostasis; it may help to improve algorithms in continuous glucose monitoring and to develop novel sensors [7, 8]. Standard electrophysiology approaches to determine glucose-dependent signal frequencies in islets require special configurations, such as sharp microelectrodes or perforated patches. These techniques are time-consuming and restricted to the observation of individual cells for a limited time. By contrast, extracellular recordings on multielectrode arrays (MEAs) offer a novel approach for physiological experiments with intact and native islet cells in a multicellular context $[7,9,10]$.

Using MEAs, we found a novel electrical signature of islet cells: slow potentials (SPs). SPs reflect the syncytial behaviour of the islets, play an important role in glucose homeostasis and are a useful biomarker of cell coupling and islet function. Our findings suggest that insulin demand may be encoded by the overall frequency of SPs rather than by the bursting behaviour of islets.

\section{Methods}

Chemicals All chemicals were obtained from Sigma-Aldrich (St. Louis, MO, USA) except for GLP-1 (Bachem Bioscience, King of Prussia, PA, USA). Nifedipine and glibenclamide were solubilised in dimethyl sulfoxide, and adrenaline was solubilised in ascorbic acid. Solvents (final concentrations $\leq 0.1 \%$, vol./vol.) were without effect on SPs.

Animals Adult (8-80 week old) $\mathrm{C} 57 \mathrm{BL} / 6$ mice were used as the wild-type (WT) animals (obtained from Bordeaux University Animal House breeding, Bordeaux, France). Age-matched conditional mice floxed (Flox: $C \times 36^{\text {Flox(CFP)/Flox(CFP) }}$ or deleted specifically in beta cells (RIP-Cre: $C x 36^{\text {Flox(CFP)/Flox(CFP) }}: R I P-C r e$ ) for $C x 36$ (also known as Gjd2) were from the Geneva colony [11]. All experimental procedures were approved by the French Ministry of Education and Research (No.01836.01).

Islet isolation and cell culture We obtained 100-200 islets per mouse and these were cultured for 2-7 days on MEAs (MEA100/10-Ti-gr and MEA200/30iR-Ti-gr, Multichannel Systems, Reuttlingen, Germany) as whole islets or partially dissociated islet cell clusters ( $>10$ cells per cluster), as previously described [12]. The use of human islets was approved by the ethics committee of Geneva University Hospital (Geneva, Switzerland). Human islets were isolated from three cadaveric non-diabetic donors (see electronic supplementary material [ESM] Table 1) at the Cell Isolation and Transplantation Center (Geneva University Hospital) [13]. After transport, the human islets were maintained in suspension for recovery $\left(25^{\circ} \mathrm{C}, 95 \% \mathrm{O}_{2},>90 \%\right.$ relative humidity) in CMRL- 
1066 medium (Invitrogen, Carlsbad, CA, USA) containing $5.6 \mathrm{mmol} / 1$ glucose, supplemented with FBS (10\% vol./vol.; Eurobio, Courtaboeuf, France), penicillin-streptomycin (1\% vol./vol.; Invitrogen, Saint Aubin, France) and L-glutamine (1\% vol./vol.; Invitrogen). The islets were subsequently cultured on MEAs in this medium for 5-13 days using the same procedure as for mouse islets. Culture media were renewed every 2-3 days.

Electrophysiology and signal analysis Extracellular recordings were performed at $37^{\circ} \mathrm{C}$ as previously described [12] in a buffer containing $\mathrm{NaCl} 135 \mathrm{mmol} / \mathrm{l}, \mathrm{KCl} 4.8 \mathrm{mmol} / \mathrm{l}, \mathrm{MgCl}_{2}$ $1.2 \mathrm{mmol} / \mathrm{l}, \mathrm{CaCl}_{2} 1.2-1.8 \mathrm{mmol} / \mathrm{l}$, HEPES $10 \mathrm{mmol} / \mathrm{l}$ and glucose as indicated (pH 7.4 adjusted with $\mathrm{NaOH}$ ). Simultaneous analogue data were acquired at $10 \mathrm{kHz}$ for all electrodes using a MEA1060-Inv-BC-Standard amplifier (Multichannel Systems; gain: 1,100; analogue filter: changed from default $10-3,000$ to $0.1-3,000 \mathrm{~Hz}$ ) and treated with MC_Rack software (Multichannel Systems, Tübingen, Germany). A $0.2-$ $700 \mathrm{~Hz}$ second-order Butterworth digital filter provided by MC_Rack software (www.multichannelsystems.com/ software/mc-rack) was used for representative traces (except in Fig. 1e and f). For offline determination of frequencies, SPs were extracted using a $0.2-2 \mathrm{~Hz}$ band-pass filter (see Fig. 1f), and detected using the threshold module of MC_Rack with a dead time (minimal period between two events) set to $500 \mathrm{~ms}$. SP frequencies were measured at steady state during the last 3-7 min of each condition.

For long-term recordings, MEAs seeded with human islet cells were connected to the amplifier and placed in a dry incubator $\left(95 \% \mathrm{O}_{2}\right)$ at $37^{\circ} \mathrm{C}$. Recordings were performed without perfusion in culture medium with $7 \mathrm{mmol} / \mathrm{l}$ glucose. The MEA was covered with a fluorinated ethylene-propylene membrane (ALA Scientific Instruments, Farmingdale, NY, USA) for gas exchange, with evaporation limited to $0.19 \pm$ $0.03 \%$ of the total volume per h (seven measures) [14]. Signals were continuously acquired at $2 \mathrm{kHz}$ and SP frequencies were determined offline using the procedure detailed above for successive periods of $10 \mathrm{~min}$ over $24 \mathrm{~h}$.

The correlation in Fig. $1 \mathrm{~g}$ was obtained with MATLAB software (MathWorks, Cambridge, UK). The relative angular position of 4,400 action potentials (APs) on their respective SPs was determined for four independent experiments in mouse islets recorded at $3-11 \mathrm{mmol} / 1$ glucose. SPs were extracted by determining their positive and negative extremes, APs were isolated using the wavelet transforms method [10]. The angular position of each AP was then computed between $0^{\circ}$ and $180^{\circ}$ (rising phase of SPs) or between $180^{\circ}$ and $360^{\circ}$ (falling phase).

Statistics Experiments were replicated on at least three MEAs with cells from different mice or donors. Results are presented as mean values with SEM for $N$ electrodes. Student's $t$ test was

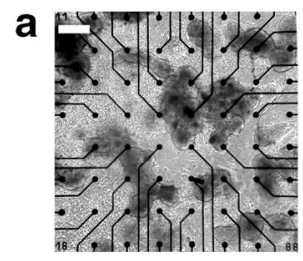

C
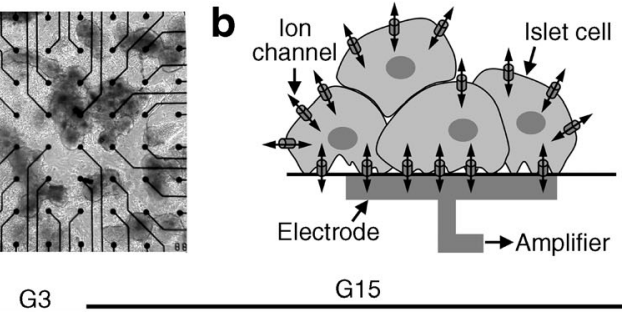

G15

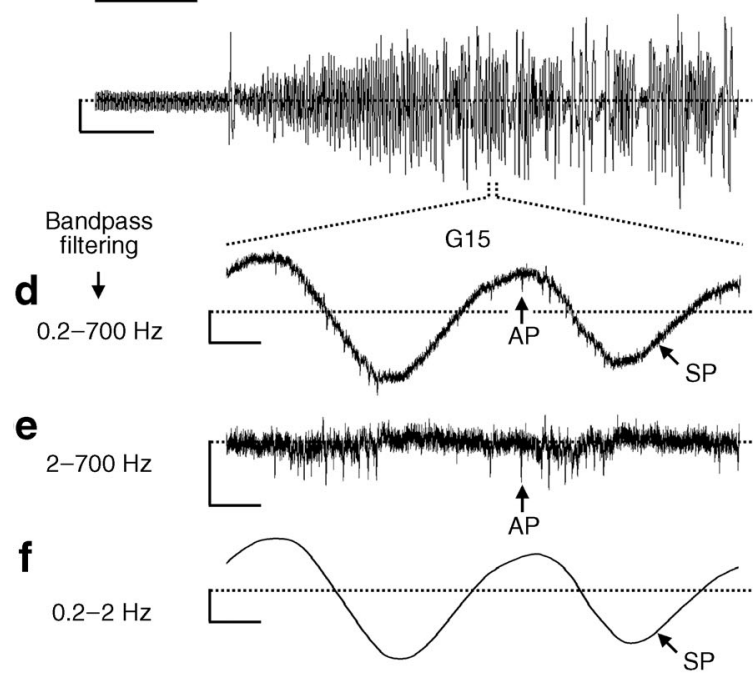

g

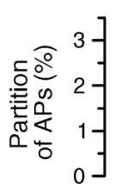

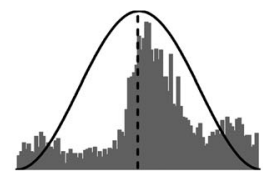

Fig. 1 Mouse islet cells cultured on MEAs generate two types of electrical signals. (a) Microscope image of intact mouse islets cultured for 3 days on a MEA. Calibration bar, $200 \mu \mathrm{m}$. (b) Scheme of the experimental setting depicting a cell cluster and an electrode. Active plasma membrane channels generate field potentials that are amplified and recorded by each electrode of the array. (c) Representative recording of electrical changes upon a rise in glucose from $3 \mathrm{mmol} / \mathrm{l}$ (G3) to $15 \mathrm{mmol} / \mathrm{l}(\mathrm{G} 15)$. (d-f) Frequency dependency of glucose-induced signals. (d) Higher temporal resolution of a portion of the recording in (c) shows rapid APs layered on slower signals, termed SPs. Both signals are observed after large band-pass filtering $(0.2-700 \mathrm{~Hz})$. (e, f) Specific bandpass filtering isolates APs $(\mathbf{e}, 2-700 \mathrm{~Hz})$ and SPs $(\mathbf{f}, 0.2-2 \mathrm{~Hz})$. Nullvoltages are indicated by horizontal broken lines $(\mathbf{c}-\mathbf{f})$. (g) Temporal correlation between APs and SPs showing that APs are mainly present during the falling phase of SPs (four independent experiments). Scale bars: horizontal (c) $1 \mathrm{~min},(\mathbf{d}-\mathbf{f}) 0.5 \mathrm{~s}$; vertical $25 \mu \mathrm{V}$

used for paired data. ANOVA with Bonferroni's or StudentNewman-Keuls correction as a post hoc test was used for comparisons between two or more groups.

\section{Results}

The electrical activity of islet cells seeded on MEAs (Fig. 1a) was recorded as illustrated in Fig. 1b for one electrode. The electrical activity of mouse islets increased when glucose concentration was raised from $3 \mathrm{mmol} / 1$ to $15 \mathrm{mmol} / \mathrm{l}$ (Fig. 1c). A 
higher temporal resolution of this glucose-induced activity (Fig. 1d) revealed the presence of two distinct and superimposed signals: rapid spikes of small amplitude (40-60 ms in duration, $10-50 \mu \mathrm{V}$ ), which have previously been characterised as APs [10]. In addition, we found slower oscillations of larger amplitude (800-1,500 ms period, 50$350 \mu \mathrm{V}$ peak-to-peak), we refer to as SPs. Differential bandpass filtering separated the two signals (Fig. 1e, f). While filtering at $2-700 \mathrm{~Hz}$ sorted the short-lasting APs, filtering at $0.2-2 \mathrm{~Hz}$ separated-out the SPs and was used for further quantification of SP frequencies. Probably due to their small amplitude, APs were not visible in $32.2 \pm 3.7 \%$ of electrodes with SPs ( $n=20$ experiments). When present, APs were downward on the majority of recordings but upward in a few cases $(96 \%$ vs $4 \%$, respectively) as in our previous report [10]. Temporal correlations between the two signals showed that APs mainly occurred during the falling $(69 \%)$ rather than the rising phase (31\%) of SPs (Fig. 1g). Both signals were observed without difference in entire islets as well as islet cell clusters, and were recorded as early as after $6 \mathrm{~h}$ in culture (not shown). Of note, SP amplitudes decreased with increasing concentration of extracellular calcium and were extinguished above $2.5 \mathrm{mmol} / \mathrm{l}$ (ESM Fig. 1).

SPs were induced by both $15 \mathrm{mmol} / \mathrm{l}$ glucose and $0.1 \mu \mathrm{mol} / 1$ glibenclamide, but not by $24 \mathrm{mmol} / \mathrm{K} \mathrm{KCl}$ (Fig. 2a and ESM Fig. 2), suggesting that SPs depend on glucose-specific mechanisms such as closure of $\mathrm{K}_{\text {ATP }}$ channels. Glucose-induced SPs were suppressed by nifedipine, an inhibitor of voltage-gated calcium channels (Fig. $2 \mathrm{~b}$ and ESM Fig. 2). We also tested the stress hormone adrenaline, an inhibitor of electrical signals in beta cells and an activator of alpha cells, at relatively high concentrations to ensure safe discrimination between the two cell types [10, 15-17]. SPs induced by glucose were reversibly inhibited by adrenaline (Fig. 2b). However, adrenaline did not affect the APs, presumably due to alpha cells being recorded together with beta cells on MEA electrodes (Fig. 2c). The dependence of SPs on elevated concentrations of glucose, which inhibit alpha cell function, indicates that SPs originated from beta cells (Fig. 2c).

We next monitored SPs in response to increasing and decreasing glucose ramps (Fig. 3a). The frequency of SPs recorded in the presence of various glucose concentrations was higher during the increasing (up) than the decreasing (down) ramp (Fig. 3b and ESM Fig. 3). SP frequency increased during the rising phase, with a median effective concentration $\left(\mathrm{EC}_{50}\right)$ of $7.5 \mathrm{mmol} / \mathrm{l}$ and a maximal effect at $10 \mathrm{mmol} / \mathrm{l}$ glucose, and then it slowed down during the decreasing phase at a faster rate, resulting in a shift of the $\mathrm{EC}_{50}$ to $8.7 \mathrm{mmol} / \mathrm{l}$. The difference in the kinetics during the increasing vs the decreasing glucose concentration resulted in a hysteresis of the up- and down-curve, which was also observed for the AP frequencies (not shown), consistent with a rapid response of beta cells to a decrease in glucose levels. We further observed that $0.5 \mathrm{pmol} / 1$

\section{a}
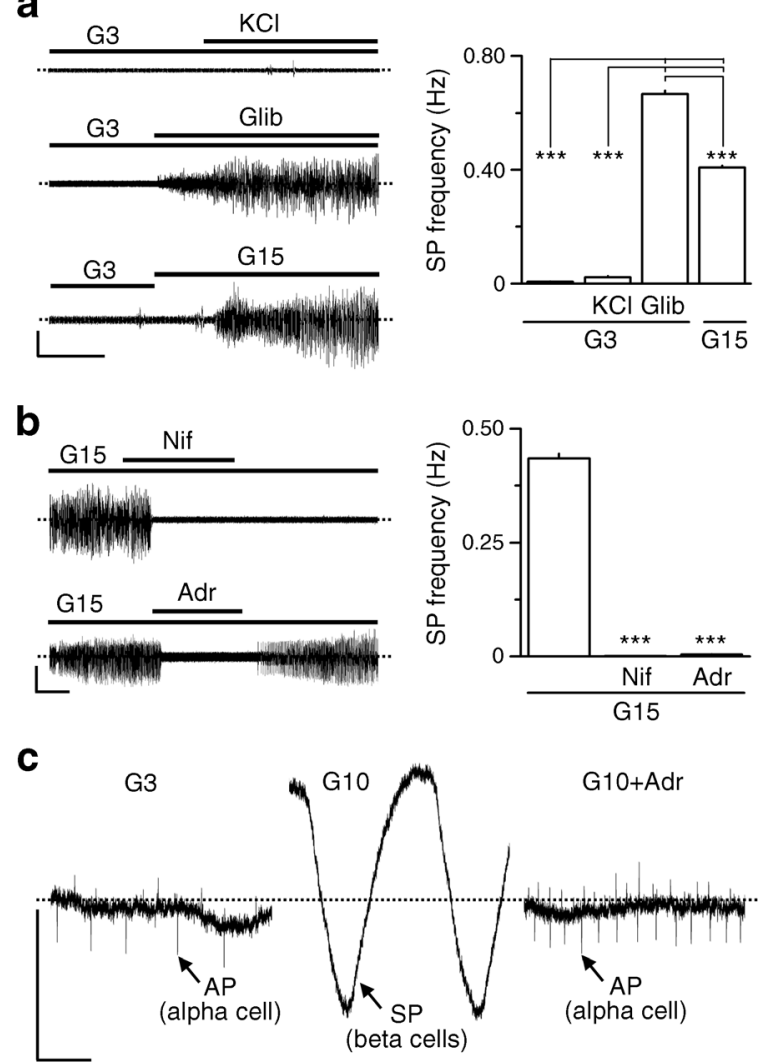

Fig. 2 SPs of mouse islet cells require $\mathrm{K}_{\mathrm{ATP}}$ as well as voltage-gated calcium channels and are generated by beta cells. (a) SPs were evoked by $15 \mathrm{mmol} / \mathrm{l}$ glucose (G15) or $100 \mathrm{nmol} / \mathrm{l}$ glibenclamide (Glib) but not by $3 \mathrm{mmol} / 1$ glucose (G3) or $24 \mathrm{mmol} / \mathrm{l} \mathrm{KCl}(\mathrm{KCl})$. Representative traces are shown and the graph gives the statistics $(n=95-377)$. (b) Glucoseinduced SPs were abolished by $25 \mu \mathrm{mol} / \mathrm{l}$ of nifedipine (Nif) or $5 \mu \mathrm{mol} / 1$ adrenaline (Adr). Representative traces are shown and the graph gives the statistics $(n=53-140) .{ }^{* * *} p<0.001$ (Bonferroni post hoc test). For higher temporal resolution, see ESM Fig. 2. (c) Alpha cells and beta cells can be recorded by the same electrode. APs are activated by low glucose (G3: $3 \mathrm{mmol} / \mathrm{l})$ or adrenaline (G10+Adr: $10 \mathrm{mmol} / \mathrm{l}$ glucose with $5 \mu \mathrm{mol} / \mathrm{l}$ adrenaline) and are attributed to alpha cells. SPs activated by high glucose (G10: $10 \mathrm{mmol} / \mathrm{l}$ ) and inhibited by adrenaline represent an electrical signature of beta cell activity. Scale bars: horizontal (a, b) $3 \mathrm{~min}$, (c) $0.5 \mathrm{~s}$; vertical $100 \mu \mathrm{V}$

GLP-1 increased the frequency of SPs (Fig. 3c and ESM Fig. 3), with a maximal effect at $50 \mathrm{pmol} / \mathrm{l}$, a concentration in the high physiological range [18].

We next asked whether SPs could be generated by individual beta cells or whether they required cell clusters. Glucoseinduced SPs were not affected by $100 \mu \mathrm{mol} / \mathrm{l}$ of two inhibitors of purinergic receptors, namely suramin and pyridoxalphosphate-6-azophenyl-2',4'-disulfonic acid (not shown). By contrast, $50 \mu \mathrm{mol} / \mathrm{l}$ carbenoxolone and $3.5 \mathrm{mmol} /$ 1 heptanol-1 [19] abolished glucose-induced SPs in a reversible manner (Fig. 4a, b). Of note, glucose-induced APs were not inhibited by $50 \mu \mathrm{mol} / \mathrm{l}$ carbenoxolone, indicating that only SPs depend on gap junction channels.

To further test this hypothesis, we explored the electrical activity of islets from transgenic mice carrying a beta cell 


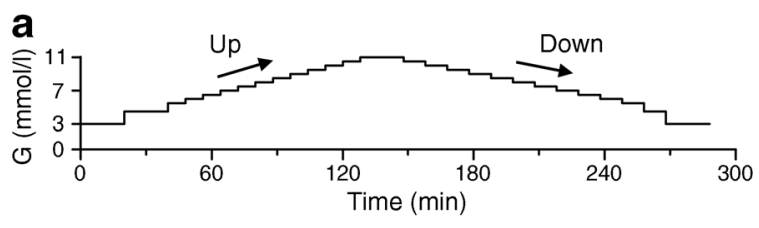

b
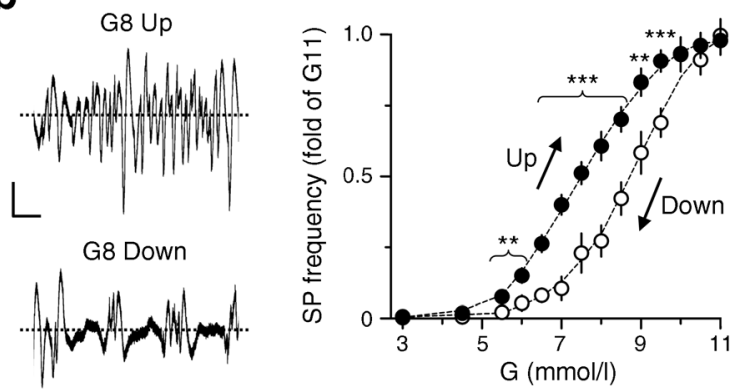

C
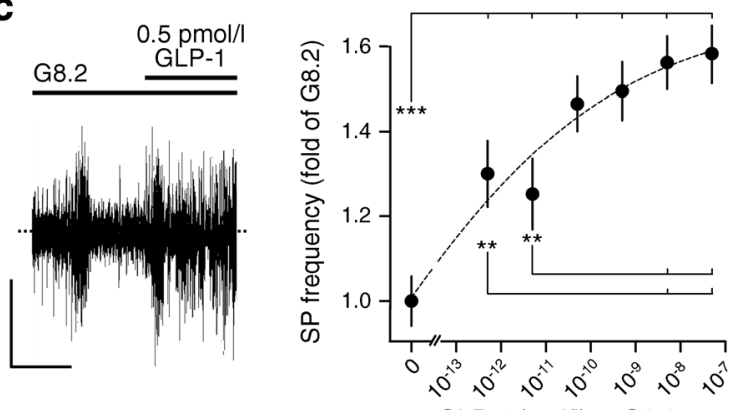

GLP-1 (mol/l) at G8.2

Fig. 3 SPs in mouse islet cells show a hysteretic glucose-dependence and are potentiated by GLP-1. (a) Protocol of glucose ramps used in (b). (b) Hysteretic response to glucose. Representative traces showing a higher frequency of SPs in the presence of $8 \mathrm{mmol} / \mathrm{l}$ glucose during the increasing (G8 Up) compared with the decreasing (G8 Down) ramp. The statistics are shown in the graph for increasing (black circles) and decreasing (white circles) glucose concentrations: $n=20 ; * * p<0.05 ; * * * p<0.001$ (paired Student's $t$ test comparing Up with Down values). (c) Representative trace showing that $0.5 \mathrm{pmol} / 1$ GLP- 1 increased the frequency of SPs induced by $8.2 \mathrm{mmol} / \mathrm{l}$ glucose. The graph shows the statistics of the effects of GLP-1 $(n=38-53) ; * * p<0.05 ; * * * p<0.001$ (Student-Newman-Keuls post hoc test). For higher temporal resolutions of (b) and (c), see ESM Fig. 3. Scale bars: horizontal (b) $10 \mathrm{~s}$, (c) 3 min; vertical $50 \mu \mathrm{V}$

specific knockout of the gene encoding connexin 36 (Cx36), the main gap junction channel in beta cells [11]. Levels of CX36 protein and beta cell coupling for $C x 36^{\text {flox(CFP) }}$ WT, Flox and RIP-Cre littermates were normal, half reduced and nil, respectively [11]. Raising glucose from $3 \mathrm{mmol} / \mathrm{l}$ to $15 \mathrm{mmol} / \mathrm{l}$ induced SPs and APs in islets of WT, but not in those of Flox and RIP-Cre mice (Fig. 4c). Thus, a 50\% decrease in CX36 protein levels is sufficient to compromise the generation of SPs.

In view of the differences in ion channels in rodent and human beta cells [1], we searched for SPs in islets isolated from three organ donors (ESM Table 1). We found that glucose generated APs and SPs in human islets (Fig. 5a), the maximal effect being reached at $8.2 \mathrm{mmol} / \mathrm{l}$ (Fig. 5b). As in a

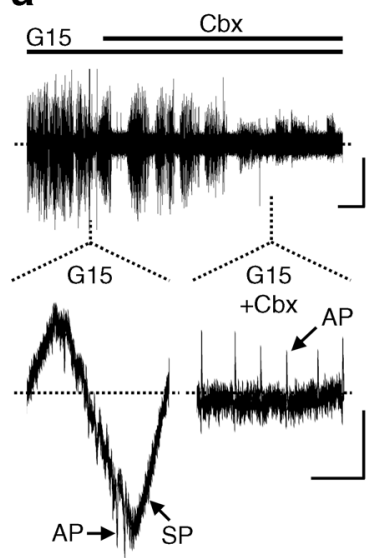

b

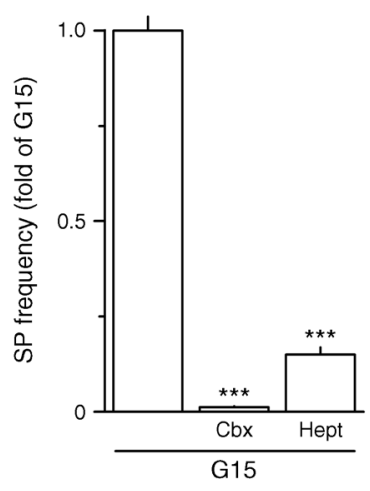

c

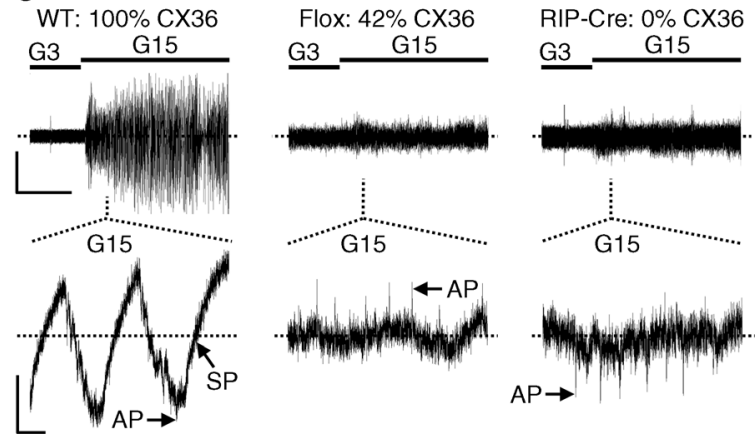

Fig. 4 SPs are dependent on CX36 gap junction channels. (a, b) $50 \mu \mathrm{mol} / 1$ carbenoxolone (Cbx) or $3.5 \mathrm{mmol} / 1$ heptanol-1 (Hept) abolishes glucose-induced SPs. (a) Recording of an experiment testing Cbx (upper trace). Higher temporal resolution (lower trace) shows that SPs, but not APs, were suppressed by the gap junction blocker. (b) $n=45-137$; $* * * p<0.001$ compared with $15 \mathrm{mmol} / \mathrm{l}$ glucose (G15) without drug; Bonferroni post hoc test. (c) The electrical response induced by G15 in islets of WT mice was not observed in islets of Flox and RIP-Cre mice, which featured reduced and nil protein levels of CX36, respectively [11]. Representative traces (above) with higher temporal resolution of electrical signals (below) observed in the presence of G15 show the presence of APs but not SPs in the islets of transgenic mice featuring reduced and nil protein levels of CX36. Traces are representative of those recorded in five to eight animals per genotype. G3, $3 \mathrm{mmol} / \mathrm{l}$ glucose. Scale bars: horizontal $5 \mathrm{~min}$ (upper traces), $0.5 \mathrm{~s}$ (lower traces); vertical $50 \mu \mathrm{V}$ (upper traces), $25 \mu \mathrm{V}$ (lower traces)

mouse islets, human SPs were reversibly suppressed by heptanol-1 (not shown). Continuous long-term recordings showed that, in human islets, glucose induced SPs with a very stable frequency over a $24 \mathrm{~h}$ period (Fig. $5 \mathrm{c}$ ).

\section{Discussion}

Our study has revealed slow extracellular field potentials induced by glucose in mouse and human islets. As depicted in Fig. 6, SP signals add to the previously described APs $[9,10$, 20] when beta cells are coupled by CX36 channels [21, 22]. APs are generated at the single-cell level [1], whereas SPs 

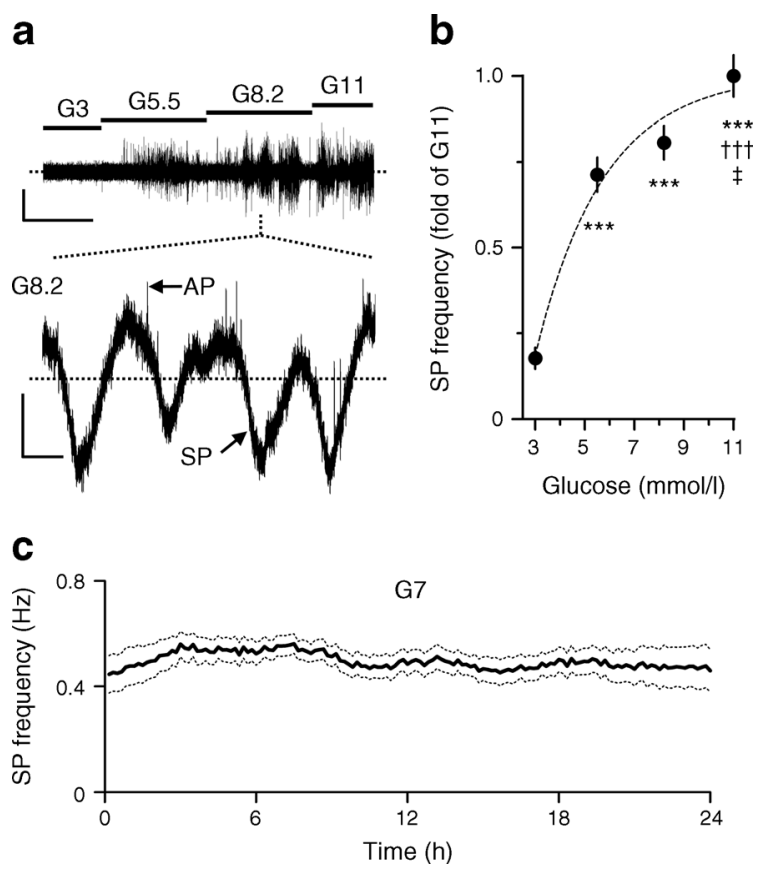

Fig. 5 Human islets show glucose-dependent SPs. (a) Representative electrical response of human islet cells to increasing glucose concentrations (upper trace). Higher temporal resolution shows the presence of both APs and SPs at $8.2 \mathrm{mmol} / 1$ glucose (G8.2, lower trace). Scale bars: horizontal $10 \mathrm{~min}$ (upper trace), $0.5 \mathrm{~s}$ (lower trace); vertical $50 \mu \mathrm{V}$ (upper trace), $25 \mu \mathrm{V}$ (lower trace). (b) Glucose concentration-dependent frequencies of SPs in human islet cells. Statistics on data pooled from three donors: $n=65 ; * * * p<0.001$ compared with the value obtained in the presence of $3 \mathrm{mmol} / \mathrm{l}$ glucose $(\mathrm{G} 3)$ or ${ }^{\dagger \dagger} p<0.001$ compared with the value obtained in the presence of $5.5 \mathrm{mmol} / 1$ glucose (G5.5), ${ }^{\star} p<0.05$ compared with the value obtained in the presence of G8.2 (Bonferroni post hoc test). (c) A $24 \mathrm{~h}$ long recording shows the stability of SP frequency evoked by $7 \mathrm{mmol} / \mathrm{l}$ glucose (G7). Solid line: mean SP frequency, dotted lines: SEM $(n=12)$

result, like local field potentials in neurons, from complex temporal and spatial summations of ion fluxes around each electrode [23]. The asymmetric temporal partition of APs on SPs (Fig. 1g) suggests a correspondence between the falling phase of SP and a depolarising stage of coupled beta cells. In fact, SPs and APs are observed at elevated glucose levels provided that beta cells contact the electrode and are coupled via connexins (Fig. 6a). By contrast, only APs are recorded at elevated glucose levels when coupling is disrupted by pharmacological or genetic intervention (Fig. 6b). At low glucose levels, when alpha cells are activated, we observed only APs in some electrodes, but never SPs (Fig. 6c; see also Fig. 2c). SPs generated by the surrounding beta cells become apparent at elevated glucose levels. Thus, SPs reflect the electrical activity and coupling of beta cells and provide important insights on the endogenous algorithms used by islets to encode the insulin demand.

The presence of APs in activated beta cells is well known [1]. They can be recorded using arrays of extracellular electrodes $[9,10,20,24]$ and their direction depends on factors such as strength of cell adhesion and the local population of

\section{a}
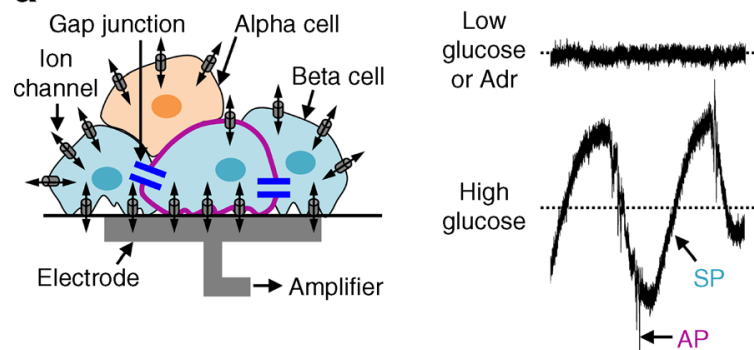

b
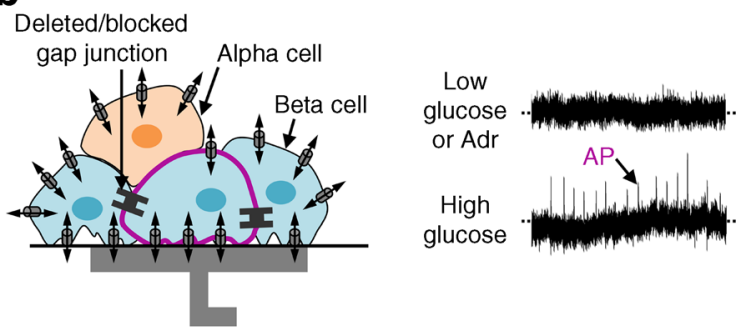

C
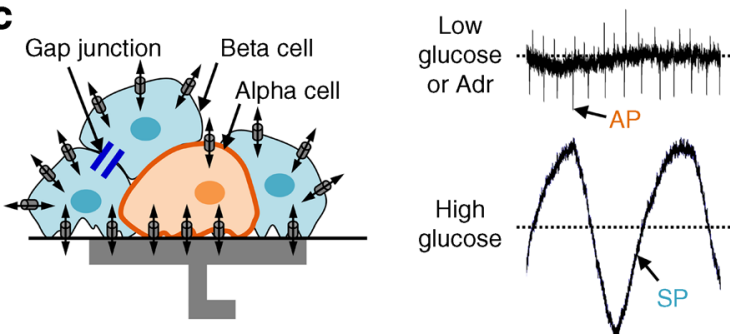

Fig. 6 SPs and APs reflect different cell-cell coupling and cell types in islets. Schematic representation for one electrode of the array of the different cell configurations (left) that lead to the signal recordings shown on the right. (a) At low glucose or in the presence of adrenaline (Adr), an islet cell cluster appears silent when only beta cells (blue) contact the microelectrode. At high glucose, such clusters generate SPs due to the synchronised activity resulting from beta cell coupling through CX36 gap junctions. The SPs are superimposed with individual APs fired by a beta cell centred on the electrode (circled in purple). (b) The decrease or suppression of gap junction coupling (either pharmacologically or by invalidation of the $C x 36$ gene) results in the inhibition of SPs but not single cell APs at elevated glucose. (c) An alpha cell (orange) centred on the electrode fires only APs in the presence of low glucose or adrenaline. Increasing glucose concentration silences alpha cells and only SPs generated by beta cell coupling are recorded. In this configuration, APs are not observed at elevated glucose due to the long distance of beta cells from the recording electrode

ion channels at the cell-electrode interface [25]. The MEA approach reduces the signal/noise ratio of APs. Consequently, registered amplitudes are significantly smaller than those reported by classical intracellular electrophysiological methods $[9,10,20,22,24,26]$. This altered signal/noise ratio renders signal recognition more difficult and requires sophisticated approaches such as wavelets and dynamic filtering [10, 27]. By contrast, the large amplitude of SPs provides easier recognition with increased precision. Similar signals have previously been recorded in rodents using single electrodes, which precludes large and statistically reliable sampling [28]. This limitation is solved using MEAs [7-10, 12, 20, 24]. Our data 
show that this approach is also applicable to human islets despite the many electrophysiological differences [29, 30], and that SPs remain stable during $24 \mathrm{~h}$ continuous recording.

Several lines of evidence indicate that SPs reflect the functional coupling of beta cells. Since antagonists of purinergic receptors did not alter SPs, the paracrine effect of the ATP coreleased with insulin $[31,32]$ is not involved. SPs but not APs were suppressed by pharmacological inhibitors of connexins or knockout of $C x 36$, encoding the only gap junction protein shown so far to couple beta cells [11,33]. Indeed, a 50\% decrease in the control islet protein levels of CX36 prevents the generation of glucose-induced SPs as shown here and largely reduces glucose-induced insulin secretion [11], suggesting a close link. Although CX36 is dispensable for the occurrence of oscillations in cytosolic calcium, it is required to synchronise the period and amplitude of these oscillations between cells of an islet [33]. Thus, SPs recorded on MEAs reflect the propagation of extracellular current flow between coupled cells, which makes them an excellent marker for normal islet function.

The physiological relevance of SPs is supported by their induction via the activation of stimulus-secretion coupling typical for beta cells $[1,29]$. SPs were induced by glucose and sulfonylurea secretagogues causing both the closure of $\mathrm{K}_{\text {ATP }}$ channels and $\mathrm{Ca}^{2+}$ oscillations [34-36]. By contrast, SPs are not evoked by high concentrations of $\mathrm{KCl}$, which probably prevents propagation by clamping all cells at the same potential. Finally, the L-type channel blocker nifedipine abolished SPs, demonstrating that calcium currents underlie these potentials. As calcium influx through L-type channels is also the main trigger of exocytosis, SPs are operationally linked to the secretory response of beta cells.

SPs were maximally stimulated in the presence of $10 \mathrm{mmol} / 1$ glucose. This concentration is lower than that which usually elicits in vitro, in a single or few steps, maximal insulin secretion [32, 37], but it is similar to that which attains the same secretory effect using a glucose ramp [38] or had been reported from in vivo patch-clamp experiments in anaesthetised mice [39]. The glucose concentrations inducing the maximal frequency of SPs coincide with those observed in humans during an OGTT [40]. GLP-1 and adrenaline increased and decreased SP frequencies, respectively, consistent with their effects on insulin secretion. Note that GLP-1 was effective at physiological picomolar concentrations as found during the postprandial period [18].

Many glucose-related events feature slow and rapid oscillations in islet cells $[4,41]$. Concomitant oscillations of membrane potential and of $\mathrm{Ca}^{2+}$ spreading over the islet have been reported recently in mouse pancreatic tissue slices [42]. Although the interval between two oscillations appears longer than for SPs, the duration of these oscillations and of SPs are quite similar [42]. Our data show that the frequency of SPs immediately depends on the ambient concentration of glucose and GLP-1. Thus, extended recording periods, such as those used in the determination of burst durations, are not necessary to evaluate beta cell function, which consequently can be determined on-line in real-time. In addition, bursts are less marked in human islets as compared with rodent islets [29]. We, therefore, propose that the overall frequency of SPs generated by the interplay of multiple cells within each islet is sufficient to encode the amount of insulin to be secreted. This also provides a novel algorithm that largely reduces computing time for a bio-artificial sensor that might mimic islet cells in real-time.

A further interesting observation concerns the difference of the effect of glucose on SPs during an increasing and a decreasing ramp. The curve is hysteretic, reflecting a reduced sensitivity of the signals towards decreasing glucose levels, reminiscent of that described in man during GTTs [40]. This control is presumably beneficial to prevent hypoglycaemia as a consequence of a sustained insulin release. As hysteresis was present in isolated islets, this safety mechanism is encoded already in the micro-organ and may occur independently from other regulatory circuits.

In conclusion, our work has identified SPs as a novel biomarker for the rapid and non-invasive testing of isolated islets and islet cell clusters. These novel 'coupling waves' specifically reflect the function of beta cells and provide for a robust signal whose detection does not require complex transformations and filtering $[43,44]$. Since SPs depend on CX36 expression, which influences the differentiation and secretory function of rodent and human islets [45-47], they should provide a suitable marker for beta cell monitoring, e.g. prior to transplantation of intact islets or clusters of surrogate insulinproducing cells. The recording of signals after $6 \mathrm{~h}$ is fully compatible with current transplantation schemes after overnight culture [48]. In addition, differentiation of stem cells into islet cells requires complex protocols and on-line monitoring as presented here may be of considerable advantage. The approach may also help to improve algorithms and sensors needed for the development of a therapeutically valuable artificial pancreas [49].

Acknowledgements Human islets were provided through the JDRF award 31-2008-416 (ECIT Islet for Basic Research program). We thank E. Pedraza (University of Bordeaux, Bordeaux, France) for critical reading of the manuscript. We gratefully acknowledge the help of the Animal Facility of the University of Bordeaux.

Funding This work was supported by grants from the French Ministry of Research (JL), FEDER BIODIA (JL and BC), the Aquitaine Regional Council (JL and BC), the French Research Agency (ANR-10-EMMA030 and ANR-13-PRTS-0017-06; JL and SR), and the Swiss National Science Foundation (310030_141162; PM). Within the framework of LabEx AMADEus (ANR-10-LABX-0042-AMADEUS), this work has benefitted from aid by the ANR under programme Initiative for Excellence IdEx Bordeaux (ANR-10-IDEX-0003-02). 
Duality of interest The authors declare that there is no duality of interest associated with this manuscript.

Contribution statement FL and MR designed research, performed experiments, researched data, and contributed to discussion and writing of the manuscript. JL designed research and contributed to discussion and writing of the manuscript. YB, IB and AP performed experiments, analysed data and contributed to writing of the manuscript. DB, TB, $\mathrm{PM}, \mathrm{BC}$ and SR contributed to the design of the work and discussion. JL is the guarantor of this work, has had full access to all the data in the study and takes responsibility for the integrity of the data and the accuracy of the data analysis. All authors contributed to the revision and approved the final version.

\section{References}

1. Ashcroft FM, Rorsman P (2012) Diabetes mellitus and the beta cell: the last ten years. Cell 148:1160-1171

2. Campbell JE, Drucker DJ (2013) Pharmacology, physiology, and mechanisms of incretin hormone action. Cell Metab 17:819-837

3. Ahren B (2000) Autonomic regulation of islet hormone secretion implications for health and disease. Diabetologia 43:393-410

4. Bertram R, Sherman A, Satin LS (2007) Metabolic and electrical oscillations: partners in controlling pulsatile insulin secretion. Am J Physiol Endocrinol Metab 293:E890-E900

5. Hodson DJ, Mitchell RK, Bellomo EA et al (2013) Lipotoxicity disrupts incretin-regulated human beta cell connectivity. J Clin Invest 123:4182-4194

6. Porksen N, Hollingdal M, Juhl C, Butler P, Veldhuis JD, Schmitz O (2002) Pulsatile insulin secretion: detection, regulation, and role in diabetes. Diabetes 51(Suppl 1):S245-S254

7. Raoux M, Bontorin G, Bornat Y, Lang J, Renaud S (2011) Bioelectronic sensing of insulin demand. In: Jung R (ed) Biohybrid systems: nerves, interfaces, and machines. Wiley-VCH Verlag GmbH \& Co. KGaA, Weinheim, pp 191-202

8. Renaud S, Catargi B, Lang J (2014) Biosensors in diabetes: how to get the most out of evolution and transpose it into a signal. IEEE Pulse 5:30-34

9. Bornat Y, Raoux M, Boutaib Y et al (2010) Detection of electrical activity of pancreatic beta-cells using micro-electrode arrays. In: 5th IEEE international symposium on electronic design, test \& applications - DELTA 2010, Ho Chi Minh City, VietNam, pp 233-236

10. Raoux M, Bornat Y, Quotb A, Catargi B, Renaud S, Lang J (2012) Non-invasive long-term and real-time analysis of endocrine cells on micro-electrode arrays. J Physiol Lond 590:1085-1091

11. Wellershaus K, Degen J, Deuchars J et al (2008) A new conditional mouse mutant reveals specific expression and functions of connexin36 in neurons and pancreatic beta-cells. Exp Cell Res 314: 997-1012

12. Nguyen QV, Caro A, Raoux M et al (2013) A novel bioelectronic glucose sensor to process distinct electrical activities of pancreatic beta-cells. Conf Proc IEEE Eng Med Biol Soc 2013:172-175

13. Bucher P, Mathe Z, Morel P et al (2005) Assessment of a novel twocomponent enzyme preparation for human islet isolation and transplantation. Transplantation 79:91-97

14. Potter SM, DeMarse TB (2001) A new approach to neural cell culture for long-term studies. J Neurosci Methods 110:17-24

15. De Marinis YZ, Salehi A, Ward CE et al (2010) GLP-1 inhibits and adrenaline stimulates glucagon release by differential modulation of $\mathrm{N}$ - and L-type $\mathrm{Ca}^{2+}$ channel-dependent exocytosis. Cell Metab 11: 543-553
16. Santana de Sa S, Ferrer R, Rojas E, Atwater I (1983) Effects of adrenaline and noradrenaline on glucose-induced electrical activity of mouse pancreatic beta cell. Exp Physiol 68:247-258

17. Rorsman P, Bokvist K, Ammala C et al (1991) Activation by adrenaline of a low-conductance $\mathrm{G}$ protein-dependent $\mathrm{K}^{+}$channel in mouse pancreatic B cells. Nature 349:77-79

18. Vilsboll T, Krarup T, Sonne J et al (2003) Incretin secretion in relation to meal size and body weight in healthy subjects and people with type 1 and type 2 diabetes mellitus. J Clin Endocrinol Metab 88:27062713

19. Meda P, Bosco D, Chanson M et al (1990) Rapid and reversible secretion changes during uncoupling of rat insulin-producing cells. J Clin Invest 86:759-768

20. Pfeiffer T, Kraushaar U, Dufer M et al (2011) Rapid functional evaluation of beta-cells by extracellular recording of membrane potential oscillations with microelectrode arrays. Pflugers Arch 462:835-840

21. Charollais A, Gjinovci A, Huarte J et al (2000) Junctional communication of pancreatic beta cells contributes to the control of insulin secretion and glucose tolerance. J Clin Invest 106:235-243

22. Zhang Q, Galvanovskis J, Abdulkader F et al (2008) Cell coupling in mouse pancreatic beta-cells measured in intact islets of Langerhans. Phil Trans R Soc A 366:3503-3523

23. Buzsaki G, Anastassiou CA, Koch C (2012) The origin of extracellular fields and currents-EEG, ECoG, LFP and spikes. Nat Rev Neurosci 13:407-420

24. Schönecker S, Kraushaar U, Dufer M et al (2014) Long-term culture and functionality of pancreatic islets monitored using microelectrode arrays. Integr Biol (Camb) 6:540-544

25. Nam Y, Wheeler BC (2011) In vitro microelectrode array technology and neural recordings. Crit Rev Biomed Eng 39:45-61

26. Meissner HP, Schmelz H (1974) Membrane potential of beta-cells in pancreatic islets. Pflugers Arch 351:195-206

27. Quotb A, Bornat Y, Raoux M, Lang J, Renaud S (2012) NeuroBetaMed: a re-configurable wavelet-based event detection circuit for in vitro biological signals. In: Circuits and systems (ISCAS), 2012 I.E. International Symposium on Circuits and Systems, pp 1532-1535

28. Palti Y, David GB, Lachov E, Mida YH, Schatzberger R (1996) Islets of Langerhans generate wavelike electric activity modulated by glucose concentration. Diabetes 45:595-601

29. Rorsman P, Braun M (2013) Regulation of insulin secretion in human pancreatic islets. Annu Rev Physiol 75:155-179

30. Braun M, Ramracheya R, Bengtsson M et al (2008) Voltage-gated ion channels in human pancreatic beta-cells: electrophysiological characterization and role in insulin secretion. Diabetes 57:1618-1628

31. Cigliola V, Chellakudam V, Arabieter W, Meda P (2012) Connexins and beta-cell functions. Diabetes Res Clin Pract 99:250-259

32. Hellman B, Dansk H, Grapengiesser E (2004) Pancreatic beta-cells communicate via intermittent release of ATP. Am J Physiol Endocrinol Metab 286:E759-E765

33. Bosco D, Haefliger JA, Meda P (2011) Connexins: key mediators of endocrine function. Physiol Rev 91:1393-1445

34. Fridlyand LE, Tamarina N, Philipson LH (2010) Bursting and calcium oscillations in pancreatic beta-cells: specific pacemakers for specific mechanisms. Am J Physiol Endocrinol Metab 299:E517-E532

35. Larsson O, Kindmark H, Brandstrom R, Fredholm B, Berggren PO (1996) Oscillations in KATP channel activity promote oscillations in cytoplasmic free $\mathrm{Ca}^{2+}$ concentration in the pancreatic beta cell. Proc Natl Acad Sci U S A 93:5161-5165

36. Grapengiesser E, Gylfe E, Hellman B (1990) Sulfonylurea mimics the effect of glucose in inducing large amplitude oscillations of cytoplasmic $\mathrm{Ca}^{2+}$ in pancreatic beta-cells. Mol Pharmacol 37:461-467

37. Henquin JC, Dufrane D, Nenquin M (2006) Nutrient control of insulin secretion in isolated normal human islets. Diabetes 55:3470-3477

38. Fujimoto W, Miki T, Ogura T et al (2009) Niflumic acid-sensitive ion channels play an important role in the induction of glucose- 
stimulated insulin secretion by cyclic AMP in mice. Diabetologia 52 : 863-872

39. Sanchez-Andres JV, Gomis A, Valdeolmillos M (1995) The electrical activity of mouse pancreatic beta-cells recorded in vivo shows glucose-dependent oscillations. J Physiol Lond 486:223-228

40. Keenan DM, Basu R, Liu Y, Basu A, Bock G, Veldhuis JD (2012) Logistic model of glucose-regulated C-peptide secretion: hysteresis pathway disruption in impaired fasting glycemia. Am J Physiol Endocrinol Metab 303:E397-E409

41. Henquin JC (1990) Role of voltage- and $\mathrm{Ca}^{2+}$-dependent $\mathrm{K}^{+}$channels in the control of glucose-induced electrical activity in pancreatic B cells. Pflugers Arch 416:568-572

42. Dolensek J, Stozer A, Skelin Klemen M, Miller EW, Slak Rupnik M (2013) The relationship between membrane potential and calcium dynamics in glucose-stimulated beta cell syncytium in acute mouse pancreas tissue slices. PLoS One 8:e82374

43. Ritzel RA, Veldhuis JD, Butler PC (2006) The mass, but not the frequency, of insulin secretory bursts in isolated human islets is entrained by oscillatory glucose exposure. Am J Physiol Endocrinol Metab 290:E750-E756
44. Porksen N, Nyholm B, Veldhuis JD, Butler PC, Schmitz O (1997) In humans at least $75 \%$ of insulin secretion arises from punctuated insulin secretory bursts. Am J Physiol 273:E908-E914

45. Carvalho CP, Barbosa HC, Britan A et al (2009) Beta cell coupling and connexin expression change during the functional maturation of rat pancreatic islets. Diabetologia 53:14281437

46. Carvalho CP, Oliveira RB, Britan A et al (2012) Impaired beta-cellbeta-cell coupling mediated by $\mathrm{Cx} 36$ gap junctions in prediabetic mice. Am J Physiol Endocrinol Metab 303:E144-E151

47. Serre-Beinier V, Bosco D, Zulianello L et al (2009) Cx36 makes channels coupling human pancreatic beta-cells, and correlates with insulin expression. Hum Mol Genet 18:428-439

48. Borot S, Niclauss N, Wojtusciszyn A et al (2011) Impact of the number of infusions on 2-year results of islet-after-kidney transplantation in the GRAGIL network. Transplantation 92: $1031-1038$

49. Steil GM, Grodsky GM (2013) The artificial pancreas: is it important to understand how the beta cell controls blood glucose? J Diabetes Sci Technol 7:1359-1369 